\title{
A New Framework for Conceptualism
}

\author{
JOHN BENGSON \\ University of Wisconsin at Madison
}

ENRICO GRUBE

University of Texas at Austin

DANIEL Z. KORMAN

University of Illinois at Urbana-Champaign

A satisfactory theory of perception must meet a variety of metaphysical and epistemological demands. What is wanted is a view that simultaneously accounts for, among other things, the epistemic significance of experience, the nature and status of illusion and hallucination, the possibility of unmediated perceptual contact with the world, the "richness" of experience, and the source of perceptual concepts. It has been argued that experience must be conceptual in order to secure the justificatory role of perceptual states; at the same time, it has been thought that such states cannot be conceptual given their phenomenological and explanatory features. Our aim is to introduce and defend a new framework for conceptualism that, by marking ontological and epistemic differences between sensory awareness and perceptual experience, promises to resolve this dispute while accounting for all of the above phenomena.

In $\S 1$, we clarify the conceptualist thesis at issue. In $\S 2$, we present and motivate the framework - a collection of theses about awareness and experience - and defend it against possible objections. In $\S 3$, we show how the framework can be used to block what we take to be the most serious threat to conceptualism: the argument from nonveridical experience. In $\S 4$, we show how the framework bears upon various further issues that arise in the debates between conceptualists and nonconceptualists, including the 
mental lives of simple-minded creatures, constraints on demonstrative concept possession, and the relation between concepts and phenomenology.

\section{Conceptualism}

Content conceptualism is the thesis that perceptual experiences, like beliefs, have fine-grained, Fregean propositions as contents. State conceptualism is the thesis that subjects must possess a concept for each item (e.g., property, relation, individual) represented by their perceptual experiences. In what follows, we shall understand conceptualism to be the conjunction of content conceptualism and state conceptualism: ${ }^{1}$

\section{Conceptualism}

For any perceptual experience $\varphi$, (i) $\varphi$ has a Fregean proposition as its content and (ii) a subject of $\varphi$ must possess a concept for each item represented by $\varphi$.

We shall call a mental state conceptual iff it has a Fregean proposition as its content and a subject of the state must have a concept for each item represented by the state. ${ }^{2}$ A mental state is nonconceptual iff it is not conceptual. In short, then, conceptualism is the thesis that all perceptual experiences are conceptual.

We recognize that various theses closely related to but distinct from what we are calling 'conceptualism' have received this label. We focus on the particular thesis that we do because, as we are about to show, it is this thesis (nothing more, nothing less) that is established by the principal motivation for conceptualism. Our intention is to start with a clean slate and not take for granted various other theses that have traditionally been associated with (what we are calling) conceptualism and which would have to be argued for separately. If certain conceptualists have independent commitments that render our framework unavailable to them, then so much the worse for those independent commitments. ${ }^{3}$

The principal motivation for conceptualism is the epistemological argument, which runs as follows. Every perceptual experience that a subject enjoys is poised to justify perceptual beliefs. ${ }^{4}$ In order for them to play this role, (i) perceptual experiences must be the sorts of things that can stand in justificatory relations to beliefs, and (ii) the subject must grasp the contents of her perceptual experiences. ${ }^{5}$ Condition (i) is satisfied only if perceptual experiences (like beliefs themselves) have Fregean propositions as contentshence, content conceptualism. Condition (ii) is satisfied only if the subject has a concept for each item represented by her perceptual experiences-hence, state conceptualism.

We recognize that the epistemological argument is controversial. But it is not our aim here to defend or otherwise evaluate this argument. ${ }^{6} \mathrm{~A}$ full defense of conceptualism requires more than just an argument for the thesis; 
what is needed, in addition, is a plausible philosophical articulation of the overall position. The purpose of this paper is to advance a new framework within which conceptualism may be defended against its most serious objections and can be shown to be a viable theory of perceptual experience. The epistemological argument will serve as one constraint on this framework: not only must the framework be consistent with the conceptualist thesis articulated above, but it also must not undercut the primary motivation for that thesis.

\section{The Framework}

In this section, we present and defend the framework. Although we are introducing the framework as part of a defense of conceptualism, as we shall see, the framework is of independent interest for the philosophy of mind and epistemology, given its implications for debates regarding the problem of perception, transparency, relationalism and representationalism, phenomenal character, the "given", and modest foundationalism.

\subsection{The Irreducibility Thesis}

At the heart of the framework are two theses about the relation between perceptual experience and sensory awareness. The first is the irreducibility thesis:

\section{The Irreducibility Thesis}

Sensory awareness is not identical to, and cannot be reduced to or analyzed in terms of, perceptual experience. ${ }^{7}$

The key idea behind the irreducibility thesis is that there are two closely related, but importantly different conscious mental states, one which relates a subject to a propositional content, and another which relates a subject, not to a propositional content, but to a property, relation, or individual. ${ }^{8}$ We reserve the label 'perceptual experience' (hereafter, simply 'experience') for the former and 'sensory awareness' (hereafter, simply 'awareness') for the latter. The English language is somewhat more cavalier (cf. White 1964). For instance, the English word 'experience', on one of its uses, purports to designate a state which relates a subject to a property, as in "She is experiencing red". 9 This use of 'experience' may be understood as designating precisely the state that we are calling awareness.

The irreducibility thesis says not only that experience and awareness are distinct, but also that the latter cannot be analyzed in terms of the former. (The significance of this further qualification for our defense of conceptualism will be made clear in $\S \S 3-4$.) We wish to emphasize that this does not rule out the possibility that experience can be analyzed in terms of awareness. ${ }^{10}$ Nor does it entail that awareness is irreducible simpliciter. Well-known 
analyses of having an experience with a given propositional content may be adapted to serve as analyses of being aware of a given property, relation, or individual: to illustrate, one may maintain (à la Tye 2000) that to be aware of a given property is to be in a state that tracks that property under optimal conditions. $^{11}$

There are two principal respects in which we take awareness and experience to differ (other differences will emerge later). First, as indicated above, experience is a state that relates a subject to a propositional content, whereas awareness is a state that relates a subject to a nonpropositional item. Consequently, the relata of experience, but not the relata of awareness, are capable of having truth values and truth conditions (or, if you prefer, accuracy conditions). Furthermore, since it is only experience that has truth (accuracy) conditions, it is only experience that may have a false content and thus be nonveridical (inaccurate). ${ }^{12}$

Second, as supposed above (recall the epistemological argument in $\S 1$ ), in order for a mental state to provide justification for belief, it must have as its content something that can stand in justificatory relations to beliefs. But only states with propositional content - experiences, for instance - can stand in justificatory relations to beliefs. States of awareness do not (and cannot) justify beliefs because they lack propositional content. This difference will play a significant role in our defense of conceptualism.

Despite their differences, we do take the two states to be tightly connected. ${ }^{13}$ We maintain that one has an experience as of something having a given sensible property only if one is aware of that property (more on this in $\S 2.2$ ). Additionally, we maintain that the properties and relations of which one is aware in having a given perceptual experience determine the sensory character of that experience, that is, what it is like sensorily for one in having that experience. ${ }^{14}$ More generally, we endorse the sensory character thesis:

\section{The Sensory Character Thesis}

The properties and relations of which one is sensorily aware determine what it is like sensorily for one.

We restrict this thesis to sensory character (i.e., what it is like sensorily) so as to leave open the question of whether there are any nonsensory aspects of phenomenology. ${ }^{15}$ (The significance of the thesis will be made clear in $\S 4$.)

Many will think that there is a straightforward means of analyzing property awareness in terms of experience: schematically, to be aware of a property $\mathrm{F}$ just is to have an experience whose content is that there is something that is F. But this proposal arguably is not even extensionally adequate. Consider cases in which one's entire visual field is filled by a single color. You close your eyes and see only black. ${ }^{16}$ You are no doubt aware of a color: black. But you do not have an experience whose content is that something is black. 
After all, not only do you not see something - not the room, not space, not anything - that is black, but you do not even seem to see something black. You simply seem to see black. (Surely this is the answer you would give to the question "What do you seem to see?" if asked.) Accordingly, the proposed analysis belies the phenomenology and, indeed, would deliver up counterexamples to widely accepted privileged access theses: it certainly does not seem introspectively to you that you are having an experience as of there being something that is black. ${ }^{17}$

Perhaps there is some way of securing a plausible analysis that does not simply make an ad hoc exception for this type of case. ${ }^{18}$ We have our doubts. Our primary contention, however, is that the irreducibility thesis is available to conceptualists and can be put to work in handling the most serious problems for conceptualism. If the epistemological argument is sound and if, as we shall argue, the irreducibility thesis is part of the best framework for defending conceptualism, then conceptualists have excellent reason to accept the irreducibility thesis. It is worth noting, however, that the irreducibility thesis also has several theoretical virtues - stemming from its applications in epistemology and the philosophy of perception - that are entirely separable from the role it will play in our defense of conceptualism. We shall mention two.

First, it provides the resources for answering the speckled hen objection as it arises for modest foundationalism. ${ }^{19}$ The objection runs as follows: When a normal, untrained subject casually observes a hen with exactly 48 visible speckles, there will be a certain specificity (or determinateness) to her encounter with the hen; after all, those speckles are all visible. To account for this specificity, the argument goes, we must suppose that she has an experience as of something being 48-speckled. If modest foundationalism is correct, she would then be immediately justified in believing that there is something 48-speckled. But (not being a savant) she surely would not be justified in believing this solely on the basis of her experience, so modest foundationalism is false. This argument may be resisted by insisting that the specificity lies, not in the content of her experience, but rather in her state of awareness. There is a highly determinate distributional property that is instantiated by the facing surface of the hen-viz., a particular way of being speckled - and she is aware of this property. ${ }^{20}$ Foundationalists would then be free to hold that the content of her experience is something far less specific (e.g., that there is something with many speckles) or far less articulate (e.g., that there is something speckled thusly), which would explain why the subject would not be immediately justified in believing that there is something 48speckled. ${ }^{21}$ This solution obviously is not available to one who rejects the irreducibility thesis and reduces property awareness to experience.

Second, the irreducibility thesis makes possible a reconciliation of two intuitively attractive, but prima facie incompatible, positions in the philosophy of perception, namely, the so-called relational and representational accounts of perception. ${ }^{22}$ Proponents of representational accounts maintain that the 
possibility of perceptual error implies that perceptual encounters are mediated by propositional contents: one stands in a perceptual relation to worldly objects and properties by having a mental state whose propositional content represents (either accurately or inaccurately) those objects and properties as being thus and so. ${ }^{23}$ Proponents of relational accounts object that we are perceptually related to worldly objects and properties in a way that is entirely unmediated: a genuine perceptual encounter does not "fall short" of the world. ${ }^{24}$ One who accepts the irreducibility thesis may accept both accounts: subjects enjoy one mediated, wholly representational relation to the world (experience) and one unmediated perceptual relation to the world (awareness). This reconciliation would not be available to one who reduces property awareness to experience. ${ }^{25}$

\subsection{The Property Awareness Thesis}

The second key element of the framework is the property awareness thesis: ${ }^{26}$

\section{The Property Awareness Thesis}

For any perceptual experience $\varphi$, the subject of $\varphi$ is sensorily aware of every sensible property represented by $\varphi$.

Since nonveridical experiences (illusions and hallucinations) typically represent sensible properties (e.g., colors) that are not instantiated by any perceived worldly object (e.g., material object), it follows that one is sometimes aware of properties that are not instantiated by any perceived worldly object. ${ }^{27}$ There is more than one way to develop the property awareness thesis. One is to insist that in such cases there is nevertheless a (non-worldly) object of perception, for instance, a mental entity or a nonexistent object, which instantiates those properties. ${ }^{28}$ Our preferred way of developing the thesis-following George Bealer (1982, 235-239), Fred Dretske (1995, 101-102; 2000, 162 ff.; 2003, 73), Colin McGinn (1999, 319-323), Michael Tye (2000, 48; 2009, 82-83), Mark Johnston (2004), Peter Forrest (2005), and David Sosa (2007, 257) - is to hold that in such cases one is aware of properties or universals that are not instantiated by any perceived object (or, perhaps, anything at all). ${ }^{29,30}$ As indicated above, one may (but need not) take property awareness to be reducible (see note 11).

The primary motivation for the property awareness thesis - and, in particular, for allowing that one can be aware of properties that are not instantiated by any perceived worldly object - is that it is needed for a fully adequate account of nonveridical experience. ${ }^{31}$ Whenever I have an experience as of something having a certain color, certainly I am conscious of that color. But if that is so, then I am aware of that color, even if I am not perceiving any worldly object that has that color. ${ }^{32}$ In addition, I can attend to the color. I may even get a good long look at the color, whether or not any worldly object that I am perceiving actually has that color. ${ }^{33}$ One cannot attend to 
something or get a good long look at something of which one is not aware. So, whenever one's experience represents a color that no perceived worldly object has, one must either be aware of an uninstantiated color or else a color instantiated by some non-worldly object of perception.

The property awareness thesis is also motivated by what is arguably the most natural account of the nature of introspective knowledge and the objects of introspective awareness. Intuitively, one comes to know what one's experiences are like, not by attending to properties of those experiences, but rather by attending to the very properties that worldly objects are experienced as having (colors, shapes, etc.). ${ }^{34}$ Any account of introspective knowledge that both respects this transparency intuition and generalizes satisfactorily to nonveridical experiences must hold that one likewise comes to know what one's nonveridical experiences are like by attending to properties that (merely) appear to be instantiated by worldly objects. Since one can attend only to that of which one is aware, it follows that one can be aware of properties that are not instantiated by any perceived worldly object. So one must be aware of the properties represented by both one's veridical and one's nonveridical experiences.

One might object that the property awareness thesis runs afoul of a causal constraint on awareness. Specifically, one might maintain that a subject is aware of something only if it causes the subject's state of awareness, and (it seems safe to assume) a property that is not instantiated by any perceived worldly object cannot have any causal impact on a subject's mental states. We reject this causal constraint, and we find no compelling reason to accept it. No one thinks that the items to which a subject is related in having a mental state must, in general, be causes of that state; the propositional content of an experience does not cause the experience. ${ }^{35}$ Nor do we in general expect properties to cause the experiences that represent them; a nonveridical experience as of something being red is not caused by the property of being red. ${ }^{36}$ So it is not obvious why we should expect the properties of which one is aware to cause one's states of awareness. We do not thereby deny either widely-accepted causal theories of perception or of object-awareness, which require only individuals (or events) to be the causes of perception or awareness. $^{37}$ Nor, of course, do we deny that there is some causal story to be told about why it is that a subject is aware of a given color when that color is not instantiated by any perceived worldly object. ${ }^{38}$ We deny only that the story will be so crude as to require that the property itself be causally responsible for the subject's state of awareness. ${ }^{39}$

\subsection{Is This Framework Compatible with Conceptualism?}

On our framework, awareness is a nonconceptual conscious mental state that neither has a Fregean proposition as its content nor is reducible to a state that does. This, however, does not render our framework incompatible with conceptualism, either in letter or in spirit. Conceptualism, as formulated 
above, does not entail that there are no nonconceptual conscious mental states. ${ }^{40}$ Nor does the principal motivation for conceptualism - the epistemological argument - establish that there are no nonconceptual conscious mental states. This argument shows only (i) that there is a conceptual mental state (call it what you will) that is always poised to justify perceptual belief and (ii) that no nonconceptual mental state justifies belief. Our framework honors both claims.

Nor does allowing nonconceptual conscious mental states run afoul of influential objections to the "given". Setting aside what exactly the given is meant to be, the reason that it is meant to be problematic is that it is the basis of perceptual belief even though it is not the sort of thing that can justify perceptual belief. ${ }^{41}$ However, in the present framework, it is experience, not awareness, that is the justificatory basis of perceptual beliefs. So, although it may well be that the deliverances of awareness deserve the elusive label 'the given', they do not have the feature that these opponents of the given find so objectionable. ${ }^{42}$

Why, then, do some conceptualists contend that every conscious mental state must be conceptual? ${ }^{43}$ One possibility is simply that they have not noticed the availability of the irreducibility thesis and (a fortiori) the availability of a view on which awareness need not be conceptual in order for experience to be conceptual. Another is that they have independent reasons for disallowing nonconceptual conscious mental states-independent, that is, of the epistemological argument. ${ }^{44}$ We wish to emphasize that such independent commitments are wholly optional and may be rejected by those who adopt our framework as a means of defending conceptualism. It is to this use of the framework that we now turn.

\section{Nonveridical Experience and Demonstrative Concepts}

\subsection{The Argument from Nonveridical Experience}

Consider a veridical visual experience of a blueberry whose surface is the fully determinate color blue ${ }_{18}$. It is natural to suppose that typical subjects of such experiences do not possess a concept for blue ${ }_{18}$ (or other such highly specific color concepts). ${ }^{45}$ If so, then conceptualism is false, because state conceptualism is false. ${ }^{46}$

We contend that such subjects will at least possess a demonstrative concept for blue ${ }_{18}$, for instance, the concept that color or thus. ${ }^{47}$ More precisely, we endorse the demonstrative thesis:

\section{The Demonstrative Thesis}

For any perceptual experience $\varphi$ and any sensible property $\psi$ represented by $\varphi$, the subject of $\varphi$ has a demonstrative concept for $\psi{ }^{48}$

The relevant demonstrative concepts may be understood to be concepts that are (i) mind-dependent, (ii) focus-dependent, and (iii) context-dependent. ${ }^{49}$ 
To say that a concept is mind-dependent (in our sense) is to say that one must stand in some conscious mental relation to its referent at the time at which the concept is acquired. To say that a concept is focus-dependent is to say that one who acquires the concept must at least be capable of singling out, or focusing one's attention upon, its referent at the time of acquisition. To say that a concept is context-dependent is to say that some element in the context in which the concept is acquired is responsible for the concept's having the referent that it does. We shall understand concepts to be abstract senses, as opposed to abilities or mental representations (e.g., words in a language of thought).

A variety of objections have been raised against this sort of appeal to demonstrative concepts. One of the most influential has been Richard Heck's argument from nonveridical experience. ${ }^{50}$ Let $\mathrm{E}$ be an illusory experience in which an object o, which is yellow ${ }_{13}$, appears red $_{27}$; and let us suppose (for ease of exposition) that no existing worldly object is red $_{27}$ and that the subject of $\mathrm{E}$ has never before seen anything $\mathrm{red}_{27}$. By the demonstrative thesis, the subject of $\mathrm{E}$ will have a demonstrative concept for $\operatorname{red}_{27}$, for instance, the concept thus. The argument from nonveridical experience may then be stated as follows:

(1) The color of o does not fix the reference of thus.

(2) The content of $\mathrm{E}$ does not fix the reference of thus.

(3) If neither the color of o nor the content of E fixes the reference of thus, then nothing fixes the reference of thus.

(4) If nothing fixes the reference of thus, then the demonstrative thesis is false.

(5) So the demonstrative thesis is false.

The reasoning behind (1) is straightforward. If the actual color of o fixes the reference of thus then thus refers to yellow 13 - which by hypothesis it does not - and E would then be veridical — which by hypothesis it is not. Conceptualists who embrace the demonstrative thesis are likewise in no position to deny (2). The content of $\mathrm{E}$ is meant to be that o is thus. The concept thus obviously cannot fix its own reference, nor is there any other constituent of the content of E that can fix its reference. ${ }^{51}$ Premise (3) is supported by the apparent lack of any other candidate reference-fixers. As for (4), if there is nothing to fix the reference of thus, then thus presumably cannot refer at all and, a fortiori, does not refer to $\operatorname{red}_{27}$. So the subject does not have a demonstrative concept for red $_{27}$ after all, in which case the demonstrative thesis is false. ${ }^{52}$

\subsection{Our Response}

We reject (3). In both veridical and nonveridical experience, the reference of the relevant demonstrative concepts is fixed by the subject's awareness of the referents themselves. We thus endorse the reference determination thesis: 


\section{The Reference Determination Thesis}

For any perceptual experience $\varphi$ and sensible property $\psi$ represented by $\varphi$, the subject of $\varphi$ has a demonstrative concept whose reference is $\psi$ because the subject is aware of $\psi$.

Returning to the case at hand, the subject of $\mathrm{E}$ is aware of $\operatorname{red}_{27}$ and, by the reference determination thesis, it is by virtue of being aware of $\operatorname{red}_{27}$ that she comes to have a demonstrative concept for red $_{27}$. This, in turn, enables her to have an experience whose partially-demonstrative content is veridical iff $\mathrm{o}$ is $\mathrm{red}_{27}$. Since o is not $\mathrm{red}_{27}$, this account delivers the desired result: $\mathrm{E}$ is nonveridical. Since it is neither any property of o nor the content of $\mathrm{E}$ that fixes the reference of thus, (3) is false. ${ }^{53}$

Both the property awareness thesis and the irreducibility thesis figure indispensably in this response. The response plainly requires that there be awareness of properties that are not instantiated by any perceived worldly objects, since (by hypothesis) no worldly object is $\operatorname{red}_{27}$. Here is why the irreducibility thesis is equally indispensable. Suppose (contrary to the irreducibility thesis) that to be aware of $\operatorname{red}_{27}$ just is to have an experience that represents red $_{27}$. Such an experience (by the demonstrative thesis) is made possible by possession of a demonstrative concept for red $_{27}$, which in turn (by the reference determination thesis) is made possible by awareness of red $_{27}$. But this - together with the envisaged reduction of awareness-generates a vicious circularity, since one would then be aware of $\operatorname{red}_{27}$ by virtue of having $\mathrm{E}$, one would have $\mathrm{E}$ partly by virtue of possessing a demonstrative concept for $\mathrm{red}_{27}$, and one would have this concept by virtue of being aware of $\operatorname{red}_{27}$.

Our response to the argument from nonveridical experience is superior to the response advanced by Bill Brewer (2005, 222-223), which involves denying premise (4). ${ }^{54}$ Brewer suggests that, in cases of illusion, the demonstrative concept fails to refer to the actual color of the object of perception, since the subject of such an experience would not acquire an ability to track the actual shade (in this case, yellow ${ }_{13}$ ) over variations in viewing conditions, which (he says, following Evans) is a prerequisite for demonstrative reference. But even supposing that Brewer is right about the constraints on demonstrative reference (we have our doubts), this cannot by itself constitute a response to the argument from nonveridical experience. The conceptualist must explain, not simply how it is that the subject fails to have an experience that represents yellow 13 , but rather how it is that the subject succeeds in having an experience that represents $\operatorname{red}_{27}$ and, in turn, how the relevant demonstrative concept comes to refer to $\operatorname{red}_{27}{ }^{55}$ Brewer supplies no such explanation. Perhaps Brewer means to deny that the nonveridical experience in question represents red $_{27}$; in other words, contra hypothesis, such a subject simply cannot have an experience as of something being $\operatorname{red}_{27}{ }^{56}$ 
But it is not plausible that the subject cannot in the envisaged case be having an experience as of something being red $_{27}$. Our framework supplies an explanation of how the subject comes to have a demonstrative concept for $\operatorname{red}_{27}$ and, therefore, avoids this implausible treatment of nonveridical experiences.

\subsection{Objections}

Our account of what fixes the reference of demonstrative concepts may seem to be in tension with our earlier account of what it takes for a concept to be demonstrative. In particular, one might worry that our account runs afoul of the context-dependence constraint, which requires that some element in the context in which the concept is acquired be responsible for the concept's having the referent that it does. ${ }^{57}$ Even supposing that one is indeed aware of the properties that objects are experienced as having in nonveridical experience, one might object that because they are not instantiated by any perceived worldly object, they are not "present" or "salient" in the context in the way that they would need to be in order to serve as reference-fixers.

There is, however, independent reason for accepting that properties that are not instantiated by any perceived worldly objects can nevertheless fix the reference of demonstrative concepts. Consider the more straightforward example of phenomenal demonstrative concepts in thought and speech. Suppose, for instance, that there is mutual knowledge among participants in a conversation both of how o appears and that o is not the color it appears to be. One who clearly intends to use the demonstrative expression 'that color' to refer to the color that o appears to be (e.g., in saying "ripe tomatoes are that color") will succeed. So it must be possible for a color that nothing in the perceived scene instantiates to fix the reference of the demonstrative expression. Or suppose that one looks at a shirt under fluorescent department store lighting and thinks to oneself that one loves that color; but later, when examining the shirt in the light of day, one may well correctly think to oneself that it turned out not to be that color after all. Such a thought could not be correct if the demonstrative concept referred to the actual color of the shirt. So there is independent reason (for conceptualists and nonconceptualists alike) to allow such properties to be reference-fixers, and thus to count as "present" or "salient".

A second objection to our response to the argument from nonveridical experience runs as follows. According to conceptualists, experience is made possible by possession of concepts for the items represented by the experience. Shall conceptualists say the same of awareness, that is, that awareness of a property is made possible by the possession of concepts for that property? If so, then the account is viciously circular, for in typical cases the only available concepts for those properties are demonstrative concepts, yet possession of those concepts was itself supposed to be made possible by the state of awareness. So they must deny that awareness of properties is dependent 
upon the possession of concepts for those properties. But in that case (the objection continues) the account is unacceptably ad hoc-for what could possibly justify the differential treatment of awareness and experience?-and seems to be in tension with the spirit (even if it is true to the letter) of conceptualism.

It should by now be clear, however, that our proposed framework has the resources to justify this differential treatment. First, there is an important ontological difference between awareness and experience. Experience, by conceptualist lights, has as its content a proposition that is constituted by concepts; having the relevant concepts can thus be seen as a prerequisite for having the relevant experiences. This first consideration obviously does not generalize to awareness, which relates subjects to nonpropositional items (properties, relations, and individuals) that are not constituted by concepts. Second, there is a crucial epistemological difference between awareness and experience. Experiences must always be poised to serve as a subject's justification for her perceptual beliefs. In order for them to be so poised, the subject must grasp their contents and their constituent concepts. Since awareness plays no justificatory role, this second consideration does not generalize to awareness either. ${ }^{58}$ And since the primary motivation for conceptualism does not tell against the differential treatment of awareness and experience, there is no interesting sense in which our account is in tension with the spirit of conceptualism.

On the contrary, as we have argued, the best response to what may well be the most serious threat to conceptualism depends (on pain of circularity) upon this differential treatment. So, to the extent that one has reasons for accepting conceptualism, one has reasons for accepting a differential treatment of awareness and experience.

\section{Further Applications}

We have shown that our framework provides conceptualists with all of the resources needed for a satisfactory answer to the argument from nonveridical experience. The framework also has broader significance for a defense of conceptualism.

Consider, for example, the objection that, even if conceptualists can somehow explain what fixes the reference of demonstrative concepts for all of the sensible properties that one encounters in perception, they must forgo the most natural explanation of how one acquires those concepts, namely, that it is the way that the properties are presented to the subject that makes the concepts available to the subject. ${ }^{59}$ Conceptualists are meant to be unable to avail themselves of this natural order of explanation because (on pain of circularity) they cannot appeal to the experience itself to explain how one acquires such concepts. But, given our framework, conceptualists can say that it is not experience but rather awareness that presents one with sensible 
properties, and that it is therefore awareness that makes concepts for those properties available to the subject. So conceptualists may, after all, help themselves to the natural explanation of how one acquires such concepts.

The present framework also has the benefit of enabling conceptualists to answer a common worry arising from reflection on the mental lives of non-human animals (and perhaps infants). ${ }^{60}$ It has been suggested that certain "simple-minded" creatures do not have the cognitive capacities needed to grasp the concepts that, by conceptualist lights, they would need to possess in order to be the subjects of experience. So the conceptualist seems forced to concede that they have no experiences, from which it may seem to follow that they lack phenomenal consciousness: there is nothing that it is like to be them. In response, let us first observe that it is hardly obvious that such creatures cannot meet the comparatively undemanding conditions for possessing the demonstrative concepts that (by conceptualist lights) would enable them to have experiences; after all, even many nonconceptualists grant that they are at least sufficiently cognitively sophisticated to have conscious representational states. ${ }^{61}$ But, even if conceptualists grant that such creatures have no experiences, by accepting our framework they will be in a position to maintain that such creatures nevertheless are aware of colors, shapes, and other sensible properties. To the extent that they are aware of such properties (and there is no obvious obstacle to that), conceptualists can allow that there is something that it is like to be them. ${ }^{62}$

It may seem to some that the demonstrative concept thesis requires the constraints on demonstrative concept possession to be too undemanding. For instance, since subjects often are unable to re-identify the properties that are represented by their experiences, we must deny that the possession of demonstrative concepts always satisfies a putative re-identification constraint (i.e., that one possesses a demonstrative concept $\mathrm{D}$ only if one is able consistently to identify a given property as falling under $\mathrm{D}$ if it does). ${ }^{63}$ Nor, on pain of circularity (of the sort described in $\S 3.2$ ), can we accept that coming to possess demonstrative concepts requires a conscious act of "demonstration" (e.g., selective attention) that has a propositional content that represents the referent of the demonstrative ${ }^{64}$ But the idea that there are substantive constraints on demonstrative concept possession remains plausible. We have provided an account of the relevant demonstrative concepts on which their possession is indeed subject to substantive constraints: one possesses such a demonstrative concept $\mathrm{D}$ for some property $\mathrm{F}$ at time $t$ only if at $t$ or some earlier time (i) one stands in a conscious mental relation to $\mathrm{F}$ (e.g., awareness), (ii) one is capable of focusing one's attention on F, and (iii) some element in the context is responsible for its being the case that $\mathrm{D}$ is a concept for F. And we have supplied a framework within which those constraints may be satisfied. ${ }^{65}$

Our framework also opens up a novel response to a concern one might have about conceptualism, arising from the possibility of shared 
phenomenology among subjects with different conceptual repertoires ${ }^{66}$ Suppose that two subjects are each viewing the same object (e.g., a patch) under optimal viewing conditions. But suppose that the two subjects have experiences with distinct demonstrative contents (e.g., one involving the demonstrative that red and another involving the demonstrative that scarlet) - because, for instance, only one is able to identify the color of the perceived object as scarlet. It nevertheless seems possible that what it is like for the two subjects is exactly the same. But since their experiences are different, mustn't the conceptualist deny that what it is like for the one is the same as what it is like for the other? No. By the sensory character thesis, it is not the contents of experience but rather the properties of which one is aware that determine their sensory phenomenology; the phenomenal sameness is thus underwritten by their being aware of the same array of properties. ${ }^{67}$

Differences in which concepts a subject possesses need not result in differences in her overall phenomenology. But this is not to say that differences in conceptual repertoires cannot give rise to phenomenological differences. The sensory character thesis says only that sensory phenomenology is fully determined by the items of which the subject is aware: in slogan form, sensory character is concept-independent. We have deliberately left open whether there are nonsensory aspects of phenomenology that might be responsive to which concepts a subject possesses (and thus concept-dependent). In this way, the present framework can vindicate the following attractive thought about the phenomenology of foreign-language experience. ${ }^{68}$ What it is like for a native speaker and a nonspeaker of a language to hear the language spoken may be different, even though there is no difference between them at the level of auditory sensation. The nonspeaker may be aware of precisely the same sensible properties (e.g., tone and pitch properties) as the native speaker, though the former's overall phenomenology remains quite different, because those sounds are, at the level of experience, very differently "conceptualized" (e.g., as being a particular phoneme or as carrying a certain meaning). ${ }^{69}$ The framework thereby allows one to capture the sense in which experience is theory-laden - that is, by having content that is highly sensitive to which concepts a subject possesses - while consistently maintaining that experiences that differ conceptually may have a common sensory character, since the latter is determined by the sensible properties of which the two speakers are aware.

We submit that the present approach offers a versatile account of a number of important elements of mentality. Conceptualism secures the epistemological significance of perceptual experience. The property awareness thesis yields a satisfactory account of nonveridical experience. It also (together with the reference determination thesis) supplies a general account of the demonstrative concepts acquired in perception and (together with the sensory character thesis) preserves the "richness" of experience and supplies an account of how 
two subjects might differ conceptually and even phenomenologically without differing at the level of sensation. And the irreducibility thesis, by allowing awareness and experience to play very different cognitive and explanatory roles, provides one justificatory mental state (experience) that makes room for perceptual misrepresentation and one non-epistemic mental state (awareness) that delivers unmediated perceptual contact, while inter alia enabling conceptualists to appeal to awareness without fear of circularity or commitment to nonconceptual bases of belief. The result is a framework that blocks the most serious threats to conceptualism while creating new avenues for solving puzzles and resolving disputes in the philosophy of perception. ${ }^{70}$

\section{Notes}

${ }^{1}$ The most prominent defenders of conceptualism are McDowell (1994) and Brewer (1999, 2005). The distinction between content conceptualism and state conceptualism can be traced to Heck (2000, 484-485).

${ }^{2}$ We employ the broad use of 'state' familiar in contemporary philosophy of mind; on this use, properties, relations, and prima facie dynamic mental phenomena (e.g., events) may qualify as states even though they are not standing conditions.

${ }^{3} \mathrm{We}$ address various independent commitments in $\S 2.3$.

${ }^{4}$ In other words, experience is a type of mental state that provides a (perhaps defeasible) reason for the subject to form corresponding beliefs; thus a given mental state would not be an experience unless its content could be such a reason for the subject.

${ }^{5}$ This premise might be motivated as follows: a subject can be justified in believing that $p$ on the basis of a mental state (e.g., perceptual experience) with the content that $p$ only if she can form the belief that $\mathrm{p}$, and she can form the belief that $\mathrm{p}$ only if she grasps $\mathrm{p}$.

${ }^{6}$ For further discussion of epistemic motivations for conceptualism, see McDowell (1994), Brewer (1999, §5.1; 2005, §1), Heck (2000, §§4-5), Byrne (2005), and Hopp (2009). See $\S 4$ for other possible motivations, e.g., involving the phenomenology of foreign-language experience.

${ }^{7}$ We do not assume that all analyses must be a priori (or conceptual) or that reductions must be a posteriori; we will use the notions of analysis and reduction interchangeably in what follows.

${ }^{8}$ Cf. Kant (1781/1787, A51-52/B75-76): “Gedanken ohne Inhalt sind leer, Anschauungen ohne Begriffe sind blind.... Deswegen darf man aber doch nicht ihren Anteil vermischen, sondern man hat große Ursache, jedes von dem andern sorgfältig abzusondern, und zu unterscheiden."

${ }^{9}$ It is also well known that the English word 'awareness' has many uses; see, e.g., Dretske (1993, 264 ff.).

${ }^{10} \mathrm{~A}$ conceptualist who adopts our framework may find it natural to analyze experience in terms of awareness and concept possession. We will not explore this possibility here.

${ }^{11}$ As observed by Pautz $(2007,515)$. There are numerous other options. For instance, one might reduce property awareness to some other wide physical state (cf. Millikan 1984 and Dretske 1995). Alternatively, one might simply identify awareness of a given property with being in the actual neural correlate of that state of awareness, or supply a reductive (Ramsified) functionalist definition of property awareness. A proponent of the irreducibility thesis who opts for any such analysis cannot, of course, then supply the same analysis for experience. For if awareness of a property and having an experience as of something having that property have the same analysis, they must - contrary to the irreducibility thesis - be one and the same state. That said, it may be open to the proponent of the irreducibility thesis to analyze awareness in 
terms of (say) tracking properties, on the one hand, and experience in terms of (say) tracking facts or states of affairs, on the other. We will not explore this possibility here.

12 There may be an attenuated sense in which awareness can be inaccurate, viz., insofar as the property of which one is aware is not instantiated by any relevant perceived worldly object. But there plainly is another sense in which there cannot be inaccurate awareness.

${ }^{13}$ The view that states as tightly connected as we take awareness and experience to be might nevertheless be distinct is not without precedent. Cf. Burge (1977) on the irreducibility of de re beliefs to de dicto beliefs; Perry $(1977,1979)$ and Lewis $(1979,1983)$ on the irreducibility of de se beliefs to de dicto beliefs; Williamson (2000, ch. 1) on the irreducibility of knowledge to a type of belief; and Crane (2001, 112-114), Forbes (2006, ch. 4), and Montague (2007) on the irreducibility of certain objectual attitudes to propositional attitudes.

${ }^{14}$ Cf. Tye $(2000,48)$ and Johnston $(2004,146)$.

${ }^{15}$ For discussion of whether there are any nonsensory aspects of phenomenology, see Strawson (1994, ch. 1), Tye (1996, 422), Siewert (1998), Horgan and Tienson (2002), Pitt (2004), Horgan and Timmons (2005), and Siegel (2006, 492 ff.).

${ }^{16}$ Or you are in a dense fog and see only white. Or a mad scientist tampers with your visual system in such as way that you see only homogeneous blue in all directions.

${ }^{17}$ That said, we do not deny that there may still be a perfectly good sense in which you can be said to be "experiencing black" in the envisaged case. As indicated above, there is a use of 'experience' that may be understood as designating precisely the state that we are calling awareness. Thus it is natural to say, in the envisaged case, that you have an experience of black, though you do not have an experience of anything being black. It is not clear that proponents of the analysis considered in the text can explain this datum.

${ }^{18}$ A plausible analysis must, among other things, deliver a satisfactory answer to the question: "What do you seem to see?". This provides a way of assessing various alternatives, e.g., that the room is black, that everything is dark (Pautz 2007, 509), that blackness is present, that it is black.

${ }^{19}$ See Sosa (2003a, 2003b). The proposal that follows differs from the responses offered by Feldman (2004) and Fumerton (2005), and avoids the difficulties that Markie (2009) claims to find with those responses.

${ }^{20}$ See Parsons (2004) for discussion of distributional properties.

${ }^{21}$ Mutatis mutandis for the novice in Sosa's $(2009,138-139)$ example of a perceptual encounter with a chessboard.

${ }^{22}$ See Crane (2006, $\left.\S \S 3-5\right)$ for a summary of the relationalism/representationalism debate.

${ }^{23}$ Cf. Tye (1995, ch. 4) and Siewert (1998, ch. 7). There may still be a respect in which the relation is unmediated ("direct") for representationalists, to the extent that subjects do not perceive worldly objects and properties by perceiving other items.

${ }^{24}$ Cf. McDowell (1982, §1), Putnam (1994, 452-454), Martin (2002, 296 ff.), and Crane $(2006,141)$.

${ }^{25}$ Schellenberg (forthcoming a) pursues a different strategy for reconciling relationalism and representationalism. In particular, she tries to secure relationalism by allowing the objects represented in an experience to play a role in individuating the experience. Yet it seems that on the proposed account perception is still ultimately understood in entirely representational terms, viz., to perceive o is a matter of having an experience with a representational content partly constituted by an object-related de re mode of presentation of o. So this seems not to deliver a wholly unmediated perceptual relation to objects and properties.

${ }^{26}$ The thesis can straightforwardly be extended to relations as well. Here we will focus solely on properties. Our understanding of the issues surrounding property awareness has been deeply influenced by Pautz (2007, esp. §2).

${ }^{27}$ We say only that nonveridical experiences typically represent such properties because there are odd exceptions, e.g., when one sees two objects - one red, the other yellow-and yet both appear red. 
${ }^{28}$ See Price (1932, ch. 5), Broad (1965), Jackson (1977), and Robinson (1994) on the former theory. See Smith (2002) and McGinn $(2004, \S 3)$ on the latter, broadly Meinongian view.

${ }^{29}$ Sturgeon $(2001,35-36)$ may belong on this list as well, as he holds that in such cases one is aware of an intentional trope. Russell $(1912,12)$, who apparently viewed the items of which one is aware (which he called 'sense-data', a term he used neutrally to pick out whatever are the immediate data of the senses) as properties or property-instances (which he seemed to count as particulars; see, e.g., Russell 1912, 109), may be regarded as a precursor of such a view.

${ }^{30}$ Some might object to this view of awareness on the grounds that there are not any uninstantiated properties (cf. Schellenberg forthcoming b, $\S 1$ ). We will not review the arguments for the necessary existence of properties here (for one such argument, see Bealer 1993, §VII). Notice, however, that the view that one is sometimes aware of uninstantiated properties is compatible with a moderate version of in re realism which permits uninstantiated nonbasic properties or universals; cf. Johnston (2004, 180-81).

${ }^{31}$ Relatedly, when combined with the irreducibility thesis, it supplies a promising resolution of "the problem of perception", that is, the problem of accounting for the apparent immediacy and directness of perception in a way that allows for nonveridical experience (see Crane 2008).

${ }^{32}$ See Pautz (2007, 504-505) for discussion of the "intuitive argument for Item-Awareness", which is closely related to this first, phenomenological point.

${ }^{33}$ Cf. Smith (2002, 224 and 237), Johnston (2004, 140), Hawthorne and Kovakovitch (2006, 178), and Tye (2009, 82-83).

${ }^{34}$ See, e.g., Tye (1995, 135-136; 2000, 45-51), Chalmers (2006, 62), and Pautz (2007, 521). One who accepts property awareness is of course not thereby committed to transparency.

${ }^{35}$ Nor, of course, when one forms a mental image of a shade, must the shade itself cause one's imaging of the shade.

${ }^{36} \mathrm{Cf}$. Tye (2000, 64): "[G]iven the right causal proximal stimulations, a brain that grows in a vat - a brain that is never properly embodied - has perceptual experiences of features to which it bears no causal connections."

${ }^{37}$ Cf. Pautz $(2007,514)$. See Grice (1961) for seminal discussion of the causal theory of perception.

${ }^{38}$ In all likelihood, the proponent of the property awareness thesis can simply "piggyback" the best causal account of nonveridical experiences, whatever that may turn out to be.

${ }^{39}$ Pautz $(2007,517-518)$ raises a different sort of objection, arising from (what he takes to be) intuitive constraints on visual awareness: first, one can be visually aware only of spatially extended items, and second, one can be visually aware only of items that look extended (cf. Schellenberg forthcoming $\mathrm{b}, \S 1$ ). Both principles are compelling when restricted to awareness of individuals (the bearers of sensible properties), but we find them far less compelling when generalized to sensible properties themselves. Take awareness of shapes, which, if these principles were correct, would be possible only if shapes both are, and look to be, extended. However, anything that looks extended must look to have some shape or other; and the shapes of shaped objects surely do not themselves look to have shapes. So one who accepted the above principles would have to deny that we are visually aware of the shapes of objects even in veridical perception. For this and other reasons, we reject those principles.

${ }^{40}$ Nor should conceptualism have this entailment; surely, it should be formulated in such a way as to allow, for instance, that craving ice cream (fearing snakes, etc.) is an irreducibly objectual (nonpropositional) attitude.

${ }^{41}$ Cf. McDowell (1994, Lecture 1), who records the influence of Sellars (1956).

${ }^{42}$ Permitting nonconceptual states is not anathema to even the most ardent opponents of the given. Even Sellars (1968, 10 ff., esp. §41; cf. 1975, 129) allows that visual sense impressions are nonconceptual, although they are "intimately related to certain other inner episodes", namely, visual perceptions, that are conceptual. Sellars compares the adoption of one nonconceptual conscious state and one conceptual conscious state to Kant's doctrine of sensibility 
and understanding. Some will discern a distinctively Kantian flavor in our framework as well.

${ }^{43}$ This may be what McDowell $(2002,457)$ has in mind when he writes: "[W]e cannot make use of the notion of an interface between mind (which inhabits the space of concepts) and world, where the world presents the mind with non-conceptual items for it to work into conceptual shape."

${ }^{44}$ Certain conceptualists may be unwilling to accept other aspects of our framework. For instance, conceptualists who accept certain strong forms of disjunctivism might object to the sensory character thesis on the grounds that the properties of which one is aware are an intolerable "common factor" between successful and unsuccessful perceptual encounters. But such strong disjunctivist theses are likewise optional, as they are neither entailed by conceptualism nor secured by the epistemological argument. (Note, however, that the present framework is consistent with McDowell's epistemological disjunctivism; cf. Byrne and Logue (2008) on some varieties of disjunctivism.)

${ }^{45}$ A concept for a property is a concept that applies to all and only instances of that property.

${ }^{46}$ Proponents of this argument, originally due to Evans $(1982,229)$, include Peacocke (1989; 1992, 111), Heck (2000, 489-490), Tye (2000, 61; 2006, 518; 2009, 105), Huemer (2001, 74-75), Kelly (2001a, 398), and Sainsbury (2005, 242-243).

${ }^{47}$ This sort of strategy originates with McDowell (1994, 56 ff.); cf. Brewer (1999, 170-174).

${ }^{48}$ Our framework in fact requires only the weaker thesis that the subject of an experience has a demonstrative concept for every sensible property represented by the experience unless she possesses a nondemonstrative concept for it, but we see no principled reason for stopping short of the stronger thesis. We do not require subjects to have demonstrative concepts for nonsensible properties represented by their experiences; any subject sophisticated enough to have experiences that represent the sorts of nonsensible properties that some take to be so represented (e.g., orthographic and semantic properties; see Peacocke 1992, 89-90) presumably will already possess some nondemonstrative concept for those properties.

${ }^{49} \mathrm{Cf}$. Chuard (2006, 188-189). See $\S 4$ for further discussion of the constraints on demonstrative concepts, including putative re-identification and demonstration constraints.

${ }^{50}$ Heck (2000, 495-499); cf. Hanna (2005, 265), Gendler and Hawthorne (2006, 16-17), and Tye $(2006,523 ; 2009,108)$. We will consider other objections in $\S 4$.

${ }^{51} \mathrm{Cf}$. Heck (2000, 496). A nonconceptualist would be in a position to resist (2), for she may hold that the (Russellian) content of E includes the property of being red 27 as a constituent and that it is this constituent of the content of $E$ that fixes the reference of the demonstrative concepts acquired in having the experience.

${ }^{52}$ We follow Heck and others by construing the objection in terms of what fixes the reference of the relevant demonstrative concepts. It may be that the objection (and our response to follow) is better construed in terms of what determines which of various concepts - with mind-independent application conditions - one acquires in experience. We will not pursue this suggestion here.

${ }^{53}$ Mutatis mutandis for Heck's $(2000,494-496)$ suggestion that there is nothing (by conceptualist lights) to fix the content of the demonstrative concept that color in a nonveridical experience whose content is that that part of the desk is that color.

${ }^{54}$ Pelling $(2007,174-177)$ advocates a different response, which likewise involves denying (4). He advises conceptualists to deny that demonstrative color concepts need to have their references fixed; it is simply a brute fact that these concepts have the referents that they do. The problem is that, if nothing fixes the reference of the relevant concepts, then there would seem to be no sense in which they can be said to be demonstrative. (They clearly do not meet the conditions for being demonstrative concepts specified in $\S 3.1$, since they do not meet the context-dependence constraint.) The problem is not merely a terminological one of deciding whether the requisite concepts deserve the label 'demonstrative'. As Heck $(2000,490)$ observes, 
conceptualists must do more than "flatly assert" that we have concepts that refer to all of the properties represented in experience; they must supply an account of "how perception makes these concepts available".

${ }^{55}$ Cf. Pelling $(2007,171)$.

${ }^{56}$ This may be what Brewer $(2005,223)$ means when he says that the subject's nonveridical experience "consists in ... a failed attempt at demonstrative reference to the specific shade in question." In recent work, Brewer (2008) has explored a nonconceptualist account of nonveridical experience.

${ }^{57}$ The requisite concepts plainly satisfy the mind-dependence constraint, for the subject stands in a conscious mental relation (awareness) to their referents (e.g., sensible properties), even in nonveridical experience. Focus-dependence is satisfied as well: one is always capable of attending to the colors that objects are experienced as having, even when no perceived worldly object has those colors.

${ }^{58}$ Additionally, on an attractive conception of perceptual justification, perceptual experience provides prima facie justification for corresponding beliefs because it relates a subject to a propositional content that is thereby presented as true (cf. Pryor 2000, 547 and Bengson 2010).

${ }^{59}$ See Heck $(2000,490-493)$ and Roskies $(2008,654-656 ; 2010$, $\S \S 3-4)$. Cf. Peacocke (2001b, $\S 3)$, Campbell (2002, 122-125), Sosa (2003a, 279), and Brewer $(2005,222)$ for relevant discussion.

${ }^{60}$ For relevant discussion, see Dretske (1993, 268), McDowell (1994, 63-65), Brewer (1999, $\S 5.3 .4)$, Peacocke (2001a, 614; 2001b, §5), Noë (2004, 184-187), and Speaks (2005).

${ }^{61}$ See, e.g., Tye (1997) and Peacocke (2001b, §5). See Allen and Bekoff (1997), Bermúdez (2003), Carruthers (2004), and Newen and Bartels (2007) for relevant discussion of animal cognition.

${ }^{62}$ Moreover, there would still be a perfectly good sense in which such creatures can be said to "experience colors". As indicated in $\$ 2.1$, there is a use of 'experience' that may be understood as designating precisely the state that we are calling awareness.

${ }^{63}$ Kelly (2001a) invokes this constraint in an argument against what we are calling the demonstrative thesis; Philippe Chuard (2006) has argued convincingly that there is no such re-identification constraint on demonstrative concept possession.

${ }^{64}$ Levine $(2008,2010)$ and Roskies $(2010)$ suggest such a constraint. Perhaps demonstratives in speech and conscious thought are subject to this constraint (Roskies 2010, 120-122). But this cannot settle the question of whether demonstratives in experience and (tacit) belief can come to be possessed only by means of a conscious act of "demonstration". Incidentally, we are willing to forfeit the label 'demonstrative concept' if the connotation of demonstrating is too strong or misleading; though we do find the label apt, in light of the character of the constraints on these concepts articulated above.

${ }^{65}$ See Chuard $(2006,188-189)$ for discussion of further constraints compatible with the present framework (in particular, the Location, Inferential, and Generality constraints).

${ }^{66}$ Cf. Peacocke (1998, 381-382; 2001b, 245), Brewer (1999, 173-174), Kelly (2001b, 603 ff.), and Sosa (2003a, $\S 6$ ).

${ }^{67}$ Brewer $(1999,173-174)$ offers a different response to this type of objection, which requires conceding that, although there is some "overlap" with respect to what it is like for two such subjects, there must still be some phenomenal difference. (Cf. Kelly 2001b, 603-605.) Our response is superior insofar as it can allow for cases in which there is no difference whatsoever with respect to what it is like for two such subjects.

${ }^{68}$ For discussion of the phenomenology of foreign-language experience, see Peacocke (1992, 89), Strawson (1994, 5 ff.), Lormand (1996), Tye (1996, 422; 2000, 60-61), Siewert (1998, 275), Horgan and Tienson (2002, §2), Fricker (2003), Pitt (2004, §2.3.3), and Siegel (2006, 490).

${ }^{69}$ Our framework does not require these cases to be understood in this way. One may instead understand them as experiential differences with no phenomenological differences, like the cases discussed in the previous paragraph. Our framework also leaves it open that which 
sensible properties one is aware of can be affected by (which is not to say entirely determined by) which concepts one possesses (cf. Johnston 2006, 283). So one may instead hold that, despite the sameness of auditory stimulus, there is a difference at the level of auditory sensation, which in turn results in a difference at the level of sensory character.

${ }^{70}$ For helpful comments and discussion, we are grateful to Derek Ball, George Bealer, Dave Chalmers, Philippe Chuard, Josh Dever, Ty Fagan, Frank Hofmann, Richard Heck, Mike Huemer, Adam Pautz, Ian Phillips, Hilary Putnam, Mark Sainsbury, Anat Schechtman, Susanna Schellenberg, David Sosa, Ernest Sosa, Jeff Speaks, Michael Tye, and Malte Willer.

\section{References}

Allen, C. and M. Bekoff. 1997. Species of mind: The philosophy and biology of cognitive ethology. Cambridge, MA: MIT Press.

Bealer, G. 1982. Quality and concept. Oxford: Clarendon Press.

Bealer, G. 1993. Universals. The Journal of Philosophy 90: 5-32.

Bengson, J. 2010. The intellectual given. PhD dissertation, University of Texas at Austin.

Bermúdez, J. 2003. Thinking without words. Oxford: Oxford University Press.

Brewer, B. 1999. Perception and reason. Oxford: Clarendon Press.

Brewer, B. 2005. Do sense experiential states have conceptual content? In E. Sosa and M. Steup, eds., Contemporary debates in epistemology. Oxford: Blackwell.

Brewer, B. 2008. How to account for illusion. In A. Haddock and F. Macpherson, eds., Disjunctivism: Perception, action, knowledge. Oxford: Oxford University Press.

Broad, C. D. 1965. The theory of sensa. In R. Swartz, ed., Perceiving, seeing, and knowing. Garden City, NY: Doubleday and Company, Inc.

Burge, T. 1977. Belief de re. The Journal of Philosophy 74: 338-362.

Byrne, A. 2005. Perception and conceptual content. In E. Sosa and M. Steup, eds., Contemporary debates in epistemology. Oxford: Blackwell.

Byrne, A. and H. Logue. 2008. Either/or. In A. Haddock and F. Macpherson, eds., Disjunctivism: Perception, action, knowledge. Oxford: Oxford University Press.

Campbell, J. 2002. Reference and consciousness. Oxford: Oxford University Press.

Carruthers, P. 2004. On being simple-minded. American Philosophical Quarterly 41: 205-220.

Chalmers, D. 2006. Perception and the fall from eden. In T. S. Gendler and J. Hawthorne, eds., Perceptual experience. Oxford: Clarendon Press.

Chuard, P. 2006. Demonstrative concepts without re-identification. Philosophical Studies 130: 153-201.

Crane, T. 2001. Elements of mind. Oxford: Oxford University Press.

Crane, T. 2006. Is there a perceptual relation? In T. S. Gendler and J. Hawthorne, eds., Perceptual experience. Oxford: Clarendon Press.

Crane, T. 2008. The problem of perception. The Stanford Encyclopedia of Philosophy (Fall Edition).

Dretske, F. 1993. Conscious experience. Mind 102: 263-283.

Dretske, F. 1995. Naturalizing the mind. Cambridge, MA: MIT Press.

Dretske, F. 2000. The mind's awareness of itself. In Perception, knowledge, and belief: Selected essays. Cambridge: Cambridge University Press.

Dretske, F. 2003. Experience as representation. Philosophical Issues 13: 67-82.

Evans, G. 1982. Varieties of reference. Oxford: Oxford University Press.

Feldman, R. 2004. Foundational justification. In J. Greco, ed., Ernest Sosa and his critics. Oxford: Blackwell.

Forbes, G. 2006. Attitude problems: An essay on linguistic intentionality. Oxford: Oxford University Press.

Forrest, P. 2005. Sense-data as universals. Philosophy and Phenomenological Research 71: 622631. 
Fricker, E. 2003. Understanding and knowledge of what is said. In A. Barber, ed., Epistemology of language. Oxford: Oxford University Press.

Fumerton, R. 2005. Speckled hens and objects of acquaintance. Philosophical Perspectives 19: 121-138.

Gendler, T. S. and J. Hawthorne. 2006. Introduction. In T. S. Gendler and J. Hawthorne, eds., Perceptual experience. Oxford: Clarendon Press.

Grice, H. P. 1961. The causal theory of perception. Proceedings of the Aristotelian Society 35: 121-153.

Hanna, R. 2005. Kant and nonconceptual content. European Journal of Philosophy 13: 247290.

Hawthorne, J. and K. Kovakovitch. 2006. Disjunctivism. Proceedings of the Aristotelian Society 80: $145-183$.

Heck, R. 2000. Nonconceptual content and the "Space of Reasons". The Philosophical Review 109: 483-524.

Hopp, W. 2009. Conceptualism and the Myth of the Given. European Journal of Philosophy 17: 363-385.

Horgan, T. and J. Tienson. 2002. The intentionality of phenomenology and the phenomenology of intentionality. In D. Chalmers, ed., Philosophy of mind: Classical and contemporary readings. Oxford: Oxford University Press.

Horgan, T. and M. Timmons. 2005. Moral phenomenology and moral theory. Philosophical Issues 15: 56-77.

Huemer, M. 2001. Skepticism and the veil of perception. New York: Rowman \& Littlefield Publishers, Inc.

Jackson, F. 1977. Perception: A representative theory. Cambridge: Cambridge University Press.

Johnston, M. 2004. The obscure object of hallucination. Philosophical Studies 120: 113-183.

Johnston, M. 2006. Better than mere knowledge? The function of sensory awareness. In T. S. Gendler and J. Hawthorne, eds., Perceptual experience. Oxford: Clarendon Press.

Kant, I. 1781/1787. Critique of pure reason.

Kelly, S. D. 2001a. Demonstrative concepts and experience. The Philosophical Review 110: 397-419.

Kelly, S. D. 2001b. The non-conceptual content of experience: Situation dependence and fineness of grain. Philosophy and Phenomenological Research 62: 601-608.

Levine, J. 2008. Demonstrative concepts. Croatian Journal of Philosophy 8: 329-336.

Levine, J. 2010. Demonstrative thought. Mind and Language 25: 169-195.

Lewis, D. 1979. Attitudes de dicto and de se. The Philosophical Review 88: 513-543.

Lewis, D. 1983. Individuation by acquaintance and by stipulation. The Philosophical Review 92: 3-32.

Lormand, E. 1996. Nonphenomenal consciousness. Noûs 30: 242-261.

Markie, P. 2009. Classical foundationalism and speckled hens. Philosophy and Phenomenological Research 79: 190-206.

Martin, M. G. F. 2002. The transparency of experience. Mind \& Language 17: 376-425.

McDowell, J. 1982. Criteria, defeasibility, and knowledge. Proceedings of the British Academy 68: 455-479.

McDowell, J. 1994. Mind and world. Cambridge, MA: Harvard University Press.

McDowell, J. 2002. The content of perceptual experience. In A. Noë, ed., Vision and mind. Cambridge, MA: MIT Press.

McGinn, C. 1999. The appearance of colour. In Knowledge and reality: Selected essays. Oxford: Clarendon Press.

McGinn, C. 2004. The objects of intentionality. In Consciousness and its objects. Oxford: Clarendon Press.

Millikan, R. 1984. Language, thought and other biological categories. Cambridge, MA: MIT Press. 
Montague, M. 2007. Against propositionalism. Noûs 41: 503-518.

Newen, A. and A. Bartels. 2007. Animal minds and the possession of concepts. Philosophical Psychology 20: 283-308.

Noë, A. 2004. Action in perception. Cambridge, MA: MIT Press.

Parsons, J. 2004. Distributional properties. In F. Jackson and G. Priest, eds., Lewisian themes: The philosophy of David K. Lewis. Oxford: Oxford University Press.

Pautz, A. 2007. Intentionalism and perceptual presence. Philosophical Perspectives 21: 495541.

Peacocke, C. 1989. Perceptual content. In J. Almog, J. Perry, and H. Wettstein, eds., Themes from Kaplan. Oxford: Oxford University Press.

Peacocke, C. 1992. A study of concepts. Cambridge, MA: MIT Press.

Peacocke, C. 1998. Nonconceptual content defended. Philosophy and Phenomenological Research 58: 381-388.

Peacocke, C. 2001a. Phenomenology and nonconceptual content. Philosophy and Phenomenological Research 62: 609-615.

Peacocke, C. 2001b. Does perception have a non-conceptual content? The Journal of Philosophy 98: 239-264.

Pelling, C. 2007. Conceptualism and the problem of illusory experience. Acta Analytica 22: 169-182.

Perry, J. 1977. Frege on demonstratives. The Philosophical Review 86: 474-497.

Perry, J. 1979. The problem of the essential indexical. Noûs 13: 3-21.

Pitt, D. 2004. The phenomenology of cognition, or what is it like to think that p? Philosophy and Phenomenological Research 69: 1-36.

Price, H. H. 1932. Perception. London: Methuen.

Pryor, J. 2000. The skeptic and the dogmatist. Noûs, 34: 517-549.

Putnam, H. 1994. Sense, nonsense, and the senses: An inquiry into the powers of the mind. The Journal of Philosophy 91: 445-517.

Robinson, H. 1994. Perception. London: Routledge.

Roskies, A. L. 2008. A new argument for nonconceptual content. Philosophy and Phenomenological Research 76: 633-659.

Roskies, A. L. 2010. 'That' response doesn't work: Against a demonstrative defense of conceptualism. Noûs 44: 112-134.

Russell, B. 1912. The problems of philosophy. Oxford: Oxford University Press.

Sainsbury, R. M. 2005. Reference without referents. Oxford: Clarendon Press.

Schellenberg, S. Forthcoming a. The particularity and phenomenology of perceptual experience. Philosophical Studies.

Schellenberg, S. Forthcoming b. Ontological minimalism about phenomenology. Philosophy and Phenomenological Research.

Sellars, W. 1956. Empiricism and the philosophy of mind. In H. Feigl and M. Scriven, eds., Minnesota Studies in the Philosophy of Science, Volume I: The Foundations of Science and the Concepts of Psychology and Psychoanalysis. University of Minnesota Press: 253-329.

Sellars, W. 1968. Science and metaphysics. London: Routledge and Kegan Paul.

Sellars, W. 1975. Epistemic principles. Reprinted in E. Sosa and J. Kim, eds., Epistemology: An anthology. 2000. Oxford: Blackwell.

Siegel, S. 2006. Which properties are represented in perception? In T. S. Gendler and J. Hawthorne, eds., Perceptual experience. Oxford: Clarendon Press.

Siewert, C. 1998. The significance of consciousness. Princeton, NJ: Princeton University Press.

Smith, A. D. 2002. The problem of perception. Cambridge, MA: Harvard University Press.

Sosa, D. 2007. Perceptual friction. Philosophical Issues 17: 245-261.

Sosa, E. 2003a. Privileged access. In Q. Smith and A. Jokic, eds., Consciousness: New philosophical perspectives. Oxford: Oxford University Press. 
Sosa, E. 2003b. Beyond internal foundations to external virtues. In L. Bonjour and E. Sosa, eds., Epistemic justification: Internalism vs. externalism, foundations vs. virtues. Oxford: Blackwell.

Sosa, E. 2009. Replies to commentators on A virtue epistemology. Philosophical Studies 144: $137-147$.

Speaks, J. 2005. Is there a problem about nonconceptual content? The Philosophical Review 114: 359-398.

Strawson, G. 1994. Mental reality. Cambridge: MIT Press.

Sturgeon, S. 2001. Matters of mind. London: Routledge.

Tye, M. 1995. Ten problems of consciousness. Cambridge: MIT Press.

Tye, M. 1996. Mental reality. The Journal of Philosophy 93: 421-424.

Tye, M. 1997. The problem of simple minds. Philosophical Studies 88: 289-317.

Tye, M. 2000. Consciousness, color, and content. Cambridge, MA: MIT Press.

Tye, M. 2006. Nonconceptual content, richness, and fineness of grain. In T. S. Gendler and J. Hawthorne, eds., Perceptual experience. Oxford: Clarendon Press.

Tye, M. 2009. Consciousness revisited: Materialism without phenomenal concepts. Cambridge, MA: MIT Press.

White, A. 1964. Attention. Oxford: Blackwell.

Williamson, T. 2000. Knowledge and its limits. Oxford: Oxford University Press. 